\title{
Common fixed points for some generalized nonexpansive mappings and nonspreading-type mappings in uniformly convex Banach spaces
}

\author{
Warunun Inthakon ${ }^{1,2^{*}}$, Attapol Kaewkhao ${ }^{1}$ and Nutchari Niyamosot ${ }^{1}$
}

\section{"Correspondence: \\ w_inthakon@hotmail.com 'Department of Mathematics, Faculty of Science, Chiang Mai University, Chiang Mai, 50200, Thailand \\ ${ }^{2}$ Centre of Excellence in Mathematics, CHE, Si Ayutthaya RD., Bangkok, 10400, Thailand}

\begin{abstract}
In this article, we study the fixed point theorems for nonspreading mappings, defined by Kohsaka and Takahashi, in Banach spaces but using the sense of norm instead of using the function $\phi$. Furthermore, we prove a weak convergence theorem for finding a common fixed point of two quasi-nonexpansive mappings having demiclosed property in a uniformly convex Banach space. Consequently, such theorem can be deduced to the case of the nonspreading type mappings and some generalized nonexpansive mappings.
\end{abstract}

MSC: 49J40; 47J20

Keywords: fixed point; common fixed point; generalized nonexpansive mapping; nonspreading mapping; uniformly convex Banach space

\section{Introduction}

Let $T$ be a mapping on a nonempty subset $E$ of a Banach space $X$. The mapping $T$ is said to be quasi-nonexpansive [1] if $F(T) \neq \emptyset$ and $\|T x-y\| \leq\|x-y\|$ for all $x \in E$ and for all $y \in F(T)$, where $F(T)$ denoted the set of all fixed points of $T$.

In 2008, Suzuki [2] introduced a condition on $T$ which is weaker than nonexpansiveness and stronger than quasi-nonexpansiveness, called condition (C) and obtained some fixed point theorems for such mappings.

Since then, Dhompongsa et al. [3] extended Suzuki's main theorems to a wider class of Banach spaces. Furthermore, the fixed point theorems of such mappings have been studied by the authors of [4-6], etc.

During the same period, Kohsaka and Takahashi [7] introduced a nonlinear mapping called nonspreading mapping in a smooth, strictly convex, and reflexive Banach space $X$ as follows:

Let $E$ be a nonempty closed and convex subset of $X$. Then, a mapping $S: E \rightarrow E$ is said to be nonspreading if

$$
\phi(S x, S y)+\phi(S y, S x) \leq \phi(S x, y)+\phi(S y, x)
$$

for all $x, y \in E$, where $\phi(x, y)=\|x\|^{2}-2\langle x, J y\rangle+\|y\|^{2}$ for all $x, y \in X$ and $J$ is the duality mapping on $E$. When $X$ is a Hilbert space, we know that $\phi(x, y)=\|x-y\|^{2}$ for all $x, y \in X$ 
so a mapping $S: E \rightarrow E$ is said to be nonspreading if

$$
2\|S x-S y\|^{2} \leq\|S x-y\|^{2}+\|x-S y\|^{2}
$$

for all $x, y \in E$.

Since then, some fixed point theorems of such mapping has been studied by many researchers such as [8-10].

To discuss about weak convergence theorems for two nonexpansive mappings $T_{1}, T_{2}$ on $E$ to itself, Takahashi and Tamura [11] constructed the following iterative scheme:

$$
\begin{aligned}
& x_{1}=x \in E, \\
& x_{n+1}=\left(1-\alpha_{n}\right) x_{n}+\alpha_{n} T_{1}\left\{\beta_{n} T_{2} x_{n}+\left(1-\beta_{n}\right) x_{n}\right\} .
\end{aligned}
$$

In 2011, Dhompongsa et al. [12] showed, by giving examples, that the class of nonspreading mappings is different from the class of mappings satisfying condition $(C)$ and proved weak convergence theorems for a common fixed point of such two mappings in Hilbert spaces by using Takahashi and Tamura's iterative scheme.

In this article, motivated by Dhompongsa et al. [12], we prove some fixed point theorems for nonspreading mappings for a general Banach space, i.e., nonspreading mappings satisfying (1.2) instead of (1.1). Furthermore, we prove a weak convergence theorem for a common fixed point of any two quasi-nonexpansive mappings having demiclosed property in a uniformly convex Banach space. Consequently, such theorem can be deduced to the case of the nonspreading type mappings and some generalized nonexpansive mappings.

\section{Preliminaries}

Let $E$ be a nonempty closed and convex subset of a Banach space $X$ and $\left\{x_{n}\right\}$ be a bounded sequence in $X$. For $x \in X$, define the asymptotic radius of $\left\{x_{n}\right\}$ at $x$ as the number

$$
r\left(x,\left\{x_{n}\right\}\right)=\limsup _{n \rightarrow \infty}\left\|x_{n}-x\right\|
$$

Let

$$
r \equiv r\left(E,\left\{x_{n}\right\}\right):=\inf \left\{r\left(x,\left\{x_{n}\right\}\right): x \in E\right\}
$$

and

$$
A \equiv A\left(E,\left\{x_{n}\right\}\right):=\left\{x \in E: r\left(x,\left\{x_{n}\right\}\right)=r\right\} .
$$

The number $r$ and the set $A$ are, respectively, called the asymptotic radius and asymptotic center of $\left\{x_{n}\right\}$ relative to $E$. It is known that $A\left(E,\left\{x_{n}\right\}\right)$ is nonempty, weakly compact and convex as $E$ is [13].

Definition 2.1 [14] A Banach space $X$ is said to have the Opial property if for each sequence $\left\{x_{n}\right\} \subset X$ weakly converging to a point $x \in X$ (denote as $x_{n}-x$ ) and for any $y \in X$ 
such that $y \neq x$ there holds

$$
\liminf _{n \rightarrow \infty}\left\|x_{n}-x\right\|<\liminf _{n \rightarrow \infty}\left\|x_{n}-y\right\|
$$

or equivalently

$$
\limsup _{n \rightarrow \infty}\left\|x_{n}-x\right\|<\limsup _{n \rightarrow \infty}\left\|x_{n}-y\right\| \text {. }
$$

Definition 2.2 The modulus of convexity of a Banach space $X$ is the function $\delta_{X}:[0,2] \rightarrow$ $[0,1]$ defined by

$$
\delta_{X}(\varepsilon)=\inf \left\{1-\left\|\frac{x+y}{2}\right\|:\|x\| \leq 1,\|y\| \leq 1,\|x-y\| \geq \varepsilon\right\},
$$

for all $\varepsilon \in[0,2]$. A Banach space $X$ is said to be uniformly convex if $\delta_{X}(0)=0$ and $\delta_{X}(\varepsilon)>0$ for all $0<\varepsilon \leq 2$.

In 2008, the following condition was defined by Suzuki [2]:

Definition 2.3 [2] Let $T$ be a mapping on a subset $E$ of Banach space $X$. Then $T$ is said to be a satisfy condition $(C)$ if

$$
\frac{1}{2}\|x-T x\| \leq\|x-y\| \quad \text { implies } \quad\|T x-T y\| \leq\|x-y\|
$$

for all $x, y \in E$.

We further have the following from [2].

Theorem 2.4 [2] Let E be a weakly compact convex subset of a uniformly convex Banach space $X$. Let $T$ be a mapping on E. Assume that $T$ satisfies condition $(C)$. Then $T$ has a fixed point.

Proposition 2.5 [2] Assume that a mapping T satisfies condition (C) and has a fixed point. Then $T$ is a quasi-nonexpansive mapping.

Lemma 2.6 [2] Let $T$ be a mapping on a closed subset E of a Banach space X. Assume that $T$ satisfies condition $(C)$. Then $F(T)$ is closed. Moreover, if $X$ is strictly convex and $E$ is convex, then $F(T)$ is also convex.

Proposition 2.7 [2] Let $T$ be a mapping on subset $E$ of Banach space $X$ with the Opial property. Assume that T satisfies condition (C). If $\left\{x_{n}\right\}$ converges weakly to $z$ and $\lim _{n \rightarrow \infty}\left\|T x_{n}-x_{n}\right\|=0$, then $T z=z$. That is $(I-T)$ is demiclosed at 0 .

In 2008, Kohsaka and Takahashi [7] introduced the following nonlinear mapping.

Definition 2.8 [7] Let $X$ be a smooth, strictly convex, and reflexive Banach space, $J$ be the duality mapping of $X$ and let $E$ be a nonempty closed convex subset of $X$. Then, a mapping 
$S: E \rightarrow E$ is said to be nonspreading if

$$
\phi(S x, S y)+\phi(S y, S x) \leq \phi(S x, y)+\phi(S y, x)
$$

for all $x, y \in E$, where $\phi(x, y)=\|x\|^{2}-2\langle x, J y\rangle+\|y\|^{2}$ for all $x, y \in X$. In the case when $X$ is a Hilbert space, $S$ is said to be nonspreading if $2\|S x-S y\|^{2} \leq\|S x-y\|^{2}+\|x-S y\|^{2}$ for all $x, y \in E$.

Theorem 2.9 [7] Let $X$ be a smooth, strictly convex, and reflexive Banach space, E be a nonempty closed convex subset of $X$ and let $S$ be a nonspreading mapping of $E$ into itself. Then the following are equivalent:

- there exists $x \in E$ such that $\left\{S^{n} x\right\}$ is bounded;

- $F(S)$ is nonempty.

In 2011, Dhompongsa et al. [12] proved that, by giving the following examples, in Banach spaces, the class of nonspreading mappings for a general Banach space and the class of mappings satisfying condition $(C)$ are different. For the sake of completeness, we give the proof.

Example 1 [12] Define a mapping $T$ on $[0,3]$ by

$$
T x= \begin{cases}0, & \text { if } x \neq 3 \\ 2, & \text { if } x=3 .\end{cases}
$$

From [2], $T$ does not satisfy condition (C). But $T$ is nonspreading. Indeed if $x=3$ and $y \neq 3$, we have

$$
2\|T x-T y\|^{2}=8<9=\|T y-x\|^{2} .
$$

It is easy to see in the other cases that $2\|T x-T y\|^{2} \leq\|x-T y\|^{2}+\|y-T x\|^{2}$.

Example 2 [12] Define a mapping $T$ on $[0,1]$ by

$$
T x=1-x \text { for all } x \in[0,1] \text {. }
$$

Thus, $T$ is nonexpansive mapping and hence it satisfies condition (C). But $T$ is not nonspreading. In fact, if $x=0$ and $y=1$, we have

$$
2\|T x-T y\|^{2}=2>0=\|x-T y\|^{2}+\|y-T x\|^{2} .
$$

The authors also studied the iterative scheme of Takahashi and Tamura [11] for approximation a common fixed point of nonspreading mappings and Suzuki's mappings in Hilbert spaces as follows:

Theorem 2.10 [12] Let E be a nonempty closed convex subset of a Hilbert space H, let $S$ be a nonspreading mapping of $E$ into itself and let $T$ be a condition (C) mapping of $E$ into 
itself such that $F(S) \cap F(T) \neq \emptyset$. Define a sequence $\left\{x_{n}\right\}$ and $\left\{z_{n}\right\}$ as follows:
(A) $\left\{\begin{array}{l}x_{1}=x \in E, \\ x_{n+1}=\alpha_{n} S\left\{\beta_{n} T x_{n}+\left(1-\beta_{n}\right) x_{n}\right\}+\left(1-\alpha_{n}\right) x_{n},\end{array}\right.$
(B) $\left\{\begin{array}{l}z_{1}=z \in E, \\ z_{n+1}=\alpha_{n} T\left\{\beta_{n} S z_{n}+\left(1-\beta_{n}\right) z_{n}\right\}+\left(1-\alpha_{n}\right) z_{n}\end{array}\right.$

for all $n \in \mathbb{N}$, where $\left\{\alpha_{n}\right\} \subset(0,1]$ and $\left\{\beta_{n}\right\} \subset[0,1]$. Then, the following hold.

- if $\liminf _{n \rightarrow \infty} \alpha_{n}\left(1-\alpha_{n}\right)>0$ and $\sum_{n=1}^{\infty} \beta_{n}<\infty$, then $\left\{x_{n}\right\}$ generated by $(A)$ and $\left\{z_{n}\right\}$ generated by $(B)$ converge weakly to $v \in F(S)$ and $u \in F(T)$, respectively;

- if $\liminf _{n \rightarrow \infty} \alpha_{n}\left(1-\alpha_{n}\right)>0$ and $\liminf _{n \rightarrow \infty} \beta_{n}\left(1-\beta_{n}\right)>0$, then $\left\{x_{n}\right\}$ generated by $(A)$ and $\left\{z_{n}\right\}$ generated by $(B)$ converge weakly to $u \in F(S) \cap F(T)$ and $v \in F(S) \cap F(T)$, respectively, where $u=\lim _{n \rightarrow \infty} P_{F(S) \cap F(T)} x_{n}$ and $v=\lim _{n \rightarrow \infty} P_{F(S) \cap F(T)} z_{n}$.

Since our purpose is to study fixed point theorems of mappings defined on uniformly convex Banach spaces, we need the following result.

Lemma 2.11 [15] Let E be a uniformly convex Banach space and $r>0$. Then there exists a strictly increasing, continuous, and convex function $g:[0,2 r] \rightarrow \mathbb{R}$ such that $g(0)=0$ and

$$
\|t x+(1-t) y\|^{2} \leq t\|x\|^{2}+(1-t)\|y\|^{2}-t(1-t) g(\|x-y\|)
$$

for all $x, y \in B_{r}$ and $t \in[0,1]$, where $B_{r}=\{z \in E:\|z\| \leq r\}$.

\section{Fixed point theorems for nonspreading mappings for a general Banach space}

We recall that $S: E \rightarrow E$ is a nonspreading mapping for a general Banach space if

$$
2\|S x-S y\|^{2} \leq\|S x-y\|^{2}+\|x-S y\|^{2} \quad \text { for all } x, y \in E .
$$

First, we consider the existence of a fixed point for such mappings in Banach spaces.

Theorem 3.1 Let X be a Banach space and $E$ be a nonempty weakly compact convex subset of $X$ such that $A\left(E,\left\{x_{n}\right\}\right)$ is singleton for all bounded sequence $\left\{x_{n}\right\}$ in $X$. If $S: E \rightarrow E$ is a nonspreading mapping for a general Banach space, then $F(S)$ is nonempty.

Proof Let $x \in E$. Since $E$ is weakly compact, $E$ is bounded and hence $\left\{S^{n} x\right\}$ is bounded $\forall n \in \mathbb{N}$. Let $y \in A\left(E,\left\{S^{n} x\right\}\right)$. By the definition of $S$, we have

$$
\left\|S^{n} x-S y\right\|^{2} \leq \frac{1}{2}\left\|S^{n} x-y\right\|^{2}+\frac{1}{2}\left\|S^{n-1} x-S y\right\|^{2} .
$$

Therefore,

$$
\begin{aligned}
\limsup _{n \rightarrow \infty}\left\|S^{n} x-S y\right\|^{2} & \leq \limsup _{n \rightarrow \infty}\left(\frac{1}{2}\left\|S^{n} x-y\right\|^{2}+\frac{1}{2}\left\|S^{n-1} x-S y\right\|^{2}\right), \\
\limsup _{n \rightarrow \infty} \frac{1}{2}\left\|S^{n} x-S y\right\|^{2} & \leq \limsup _{n \rightarrow \infty} \frac{1}{2}\left\|S^{n} x-y\right\|^{2}
\end{aligned}
$$


thus, we have $\lim \sup _{n \rightarrow \infty}\left\|S^{n} x-S y\right\|^{2} \leq \limsup _{n \rightarrow \infty}\left\|S^{n} x-y\right\|^{2}$. This implies that $S y \in$ $A\left(E,\left\{S^{n} x\right\}\right)$. By the uniqueness of $A\left(E,\left\{S^{n} x\right\}\right)$, we have $S y=y$ and hence $F(S)$ is nonempty.

It follows from the fact that, in a uniformly convex Banach space, the asymptotic center of a bounded sequence with respect to a bounded closed convex subset is singleton. So, we have the following.

Theorem 3.2 Let $X$ be a uniformly convex Banach space and $E$ be a nonempty weakly compact convex subset of $X$. If $S: E \rightarrow E$ is a nonspreading mapping for a general Banach space, then $F(S)$ is nonempty.

Proposition 3.3 Let $X$ be a Banach space and $E$ be a nonempty subset of $X$. If $S: E \rightarrow E$ is a nonspreading mapping for a general Banach space and $F(S) \neq \emptyset$. Then $S$ is a quasinonexpansive mapping.

Proof Let $x \in E$ and $y \in F(S)$. By the definition of $S$, we have

$$
2\|S x-y\|^{2}=2\|S x-S y\|^{2} \leq\|S x-y\|^{2}+\|x-S y\|^{2} .
$$

Therefore, $\|S x-y\|^{2} \leq\|x-S y\|^{2}=\|x-y\|^{2}$ and hence the proof is complete.

Theorem 3.4 Let $X$ be a uniformly convex Banach space and $E$ be a nonempty weakly compact convex subset of $X$. Assume that $S: E \rightarrow E$ is a nonspreading mapping for a general Banach space and $T: E \rightarrow E$ satisfies condition (C). If $S$ and $T$ are commutative, then $F(S) \cap F(T) \neq \emptyset$.

Proof By Theorem 2.4 and Lemma 2.6, we have $F(T)$ is nonempty, closed, and convex. By the commutative of $S$ and $T$, we have $S x=S(T x)=T(S x)$, and hence $S x \in F(T)$ for all $x \in F(T)$. Therefore, $S: F(T) \rightarrow F(T)$. Since $E$ is weakly compact convex and $F(T)$ is a closed subset of $E, F(T)$ is weakly compact convex. By Theorem 3.2, we have $F(S) \neq \emptyset$. So there exists $y \in F(S)$ such that $y=S y \in F(T)$ which implies that $y \in F(S) \cap F(T)$.

Open problem Can Theorem 3.4 be improved to a commutative family $\mathcal{F}$ of nonspreading mappings for a general Banach space when $\mathcal{F}$ generates a left reversible semigroup (i.e., any two right ideals have nonvoid intersection) (see [16, 17])?

We show the demiclosedness of a nonspreading mapping for a general Banach space as follows:

Theorem 3.5 Let $X$ be a Banach space having Opial property and $E$ be a nonempty closed convex subset of $X$. Assume that $S: E \rightarrow E$ is a nonspreading mapping for a general Banach space. If $\left\{x_{n}\right\}$ is a sequence in $E$ such that $x_{n} \rightarrow x$ and $\lim _{n \rightarrow \infty}\left\|S x_{n}-x_{n}\right\|=0$, then $x \in F(S)$.

Proof Let $x_{n} \rightarrow x$ and $\lim _{n \rightarrow \infty}\left\|S x_{n}-x_{n}\right\|=0$. Assume that $S x \neq x$. By Opial property of $X$, we have

$$
\limsup _{n \rightarrow \infty}\left\|x_{n}-x\right\|^{2}<\limsup _{n \rightarrow \infty}\left\|x_{n}-S x\right\|^{2}
$$


By the definition of $S$, we have

$$
\begin{aligned}
\left\|x_{n}-S x\right\|^{2} & \leq\left(\left\|x_{n}-S x_{n}\right\|+\left\|S x_{n}-S x\right\|\right)^{2} \\
& \leq\left\|x_{n}-S x_{n}\right\|^{2}+2\left\|x_{n}-S x_{n}\right\|\left\|S x_{n}-S x\right\|+\frac{1}{2}\left\|S x_{n}-x\right\|^{2}+\frac{1}{2}\left\|x_{n}-S x\right\|^{2} .
\end{aligned}
$$

Since $x_{n} \rightarrow x,\left\{x_{n}\right\}$ is bounded and hence $\left\{S x_{n}-S x\right\}$ is bounded. Thus $\lim _{n \rightarrow \infty}\left\|S x_{n}-x_{n}\right\|=$ 0 implies that

$$
\begin{aligned}
\limsup _{n \rightarrow \infty}\left\|x_{n}-S x\right\|^{2} & \leq \limsup _{n \rightarrow \infty}\left\|S x_{n}-x\right\|^{2} \\
& \leq \limsup _{n \rightarrow \infty}\left(\left\|S x_{n}-x_{n}\right\|+\left\|x_{n}-x\right\|\right)^{2} .
\end{aligned}
$$

By the boundedness of $\left\{x_{n}-x\right\}$ and $\lim _{n \rightarrow \infty}\left\|S x_{n}-x_{n}\right\|=0$, we have

$$
\limsup _{n \rightarrow \infty}\left\|x_{n}-S x\right\|^{2} \leq \limsup _{n \rightarrow \infty}\left\|x_{n}-x\right\|^{2}
$$

which is a contradiction. Thus we have $x \in F(S)$.

Lemma 3.6 Let $X$ be a Banach space. Let $E$ be a nonempty closed convex subset of $X$. If $S: E \rightarrow E$ and $T: E \rightarrow E$ are quasi-nonexpansive mappings such that $F(S) \cap F(T) \neq \emptyset$. Let $\left\{x_{n}\right\}$ be defined as

$$
\left\{\begin{array}{l}
x_{1}=x \in E, \\
x_{n+1}=\alpha_{n} S\left\{\beta_{n} T x_{n}+\left(1-\beta_{n}\right) x_{n}\right\}+\left(1-\alpha_{n}\right) x_{n}
\end{array}\right.
$$

for all $n \in \mathbb{N}$, where $\left\{\alpha_{n}\right\} \subset(0,1)$ and $\left\{\beta_{n}\right\} \subset(0,1)$.

Then $\lim _{n \rightarrow \infty}\left\|x_{n}-w\right\|$ exists for all $w \in F(T) \cap F(S)$ and $\left\{x_{n}\right\}$ is bounded.

Proof Let $w \in F(S) \cap F(T)$ and $y_{n}=\beta_{n} T x_{n}+\left(1-\beta_{n}\right) x_{n}$. By the quasi-nonexpansiveness of $S$ and $T$, we have

$$
\begin{aligned}
\left\|S y_{n}-w\right\| & \leq\left\|y_{n}-w\right\| \\
& =\left\|\beta_{n} T x_{n}+\left(1-\beta_{n}\right) x_{n}-w\right\| \\
& \leq \beta_{n}\left\|x_{n}-w\right\|+\left(1-\beta_{n}\right)\left\|x_{n}-w\right\| \\
& =\left\|x_{n}-w\right\| .
\end{aligned}
$$

By (3.1) we have,

$$
\begin{aligned}
\left\|x_{n+1}-w\right\| & =\left\|\alpha_{n} S y_{n}+\left(1-\alpha_{n}\right) x_{n}-w\right\| \\
& \leq \alpha_{n}\left\|S y_{n}-w\right\|+\left(1-\alpha_{n}\right)\left\|x_{n}-w\right\| \\
& \leq \alpha_{n}\left\|x_{n}-w\right\|+\left(1-\alpha_{n}\right)\left\|x_{n}-w\right\| \\
& =\left\|x_{n}-w\right\| .
\end{aligned}
$$


We can conclude by induction that $\left\|x_{n}-w\right\| \leq\|x-w\|$ for all $n \in \mathbb{N}$. This imply that $\left\{\left\|x_{n}-w\right\|\right\}$ is a decreasing and bounded sequence and hence $\lim _{n \rightarrow \infty}\left\|x_{n}-w\right\|$ exists. Furthermore, $\left\{x_{n}\right\}$ is bounded since $\left\|x_{n}\right\| \leq\left\|x_{n}-w\right\|+\|w\|$.

Now, we are in a position to prove our main result.

Theorem 3.7 Let X be a uniformly convex Banach space having Opial property. Let E be a nonempty closed convex subset of $X$. If $S: E \rightarrow E$ and $T: E \rightarrow E$ are quasi-nonexpansive mappings having demiclosed property. Assume that $F(S) \cap F(T) \neq \emptyset$. Let $\left\{x_{n}\right\}$ be defined as

$$
\left\{\begin{array}{l}
x_{1}=x \in E, \\
x_{n+1}=\alpha_{n} S\left\{\beta_{n} T x_{n}+\left(1-\beta_{n}\right) x_{n}\right\}+\left(1-\alpha_{n}\right) x_{n}
\end{array}\right.
$$

for all $n \in \mathbb{N}$, where $\left\{\alpha_{n}\right\} \subset(0,1)$ and $\beta_{n} \subset(0,1)$.

Then $\liminf _{n \rightarrow \infty} \alpha_{n}\left(1-\alpha_{n}\right)>0$ and $\liminf _{n \rightarrow \infty} \beta_{n}\left(1-\beta_{n}\right)>0$ imply that $x_{n} \rightarrow v \in F(S) \cap$ $F(T)$.

Proof Let $w \in F(S) \cap F(T)$. As in the proof in Lemma 3.6, we have $\left\|x_{n}-w\right\| \leq\|x-w\|$ for all $n \in \mathbb{N}$. Using Lemma 2.11, we put $r=\|x-w\|$ so that there exists a strictly increasing, continuous, and convex function $g:[0,2 r] \rightarrow \mathbb{R}$ such that $g(0)=0$ and

$$
\begin{aligned}
\left\|y_{n}-w\right\|^{2} & =\left\|\beta_{n}\left(T x_{n}-w\right)+\left(1-\beta_{n}\right)\left(x_{n}-w\right)\right\|^{2} \\
& \leq \beta_{n}\left\|T x_{n}-w\right\|^{2}+\left(1-\beta_{n}\right)\left\|x_{n}-w\right\|^{2}-\beta_{n}\left(1-\beta_{n}\right) g\left(\left\|T x_{n}-x_{n}\right\|\right) .
\end{aligned}
$$

Hence, by the quasi-nonexpansiveness of $T$, we obtain

$$
\begin{aligned}
\left\|y_{n}-w\right\|^{2} & \leq\left\|x_{n}-w\right\|^{2}-\beta_{n}\left(1-\beta_{n}\right) g\left(\left\|T x_{n}-x_{n}\right\|\right) \\
& \leq\left\|x_{n}-w\right\|^{2} .
\end{aligned}
$$

From $\left\|x_{n+1}-w\right\|^{2}=\left\|\alpha_{n}\left(S y_{n}-w\right)+\left(1-\alpha_{n}\right)\left(x_{n}-w\right)\right\|^{2}$ and (3.3), we put $r=\|x-w\|$ in Lemma 2.11 again to get a strictly increasing, continuous, and convex function $g:[0,2 r] \rightarrow$ $\mathbb{R}$ such that $g(0)=0$ and

$$
\left\|x_{n+1}-w\right\|^{2} \leq \alpha_{n}\left\|S y_{n}-w\right\|^{2}+\left(1-\alpha_{n}\right)\left\|x_{n}-w\right\|^{2}-\alpha_{n}\left(1-\alpha_{n}\right) g\left(\left\|S y_{n}-x_{n}\right\|\right) .
$$

By the quasi-nonexpansiveness of $S$ and from (3.3), we obtain

$$
\begin{aligned}
\left\|x_{n+1}-w\right\|^{2} & \leq \alpha_{n}\left\|y_{n}-w\right\|^{2}+\left(1-\alpha_{n}\right)\left\|x_{n}-w\right\|^{2}-\alpha_{n}\left(1-\alpha_{n}\right) g\left(\left\|S y_{n}-x_{n}\right\|\right) \\
& \leq \alpha_{n}\left\|x_{n}-w\right\|^{2}+\left(1-\alpha_{n}\right)\left\|x_{n}-w\right\|^{2}-\alpha_{n}\left(1-\alpha_{n}\right) g\left(\left\|S y_{n}-x_{n}\right\|\right) \\
& =\left\|x_{n}-w\right\|^{2}-\alpha_{n}\left(1-\alpha_{n}\right) g\left(\left\|S y_{n}-x_{n}\right\|\right) .
\end{aligned}
$$

Hence

$$
\alpha_{n}\left(1-\alpha_{n}\right) g\left(\left\|S y_{n}-x_{n}\right\|\right) \leq\left\|x_{n}-w\right\|^{2}-\left\|x_{n+1}-w\right\|^{2} .
$$


Since $\liminf \operatorname{in}_{n \rightarrow \infty} \alpha_{n}\left(1-\alpha_{n}\right)>0$, there exist $k_{1}>0$ and $N \in \mathbb{N}$ such that

$$
\alpha_{n}\left(1-\alpha_{n}\right) \geq k_{1}, \quad \forall n \geq N
$$

By Lemma 3.6, we have

$$
0=\limsup _{n \rightarrow \infty}\left(\left\|x_{n}-w\right\|^{2}-\left\|x_{n+1}-w\right\|^{2}\right)
$$

and hence

$$
0 \geq \limsup _{n \rightarrow \infty} \alpha_{n}\left(1-\alpha_{n}\right) g\left(\left\|S y_{n}-x_{n}\right\|\right) \geq k_{1} \limsup _{n \rightarrow \infty} g\left(\left\|S y_{n}-x_{n}\right\|\right) .
$$

Since $k_{1}>0$, we have $\limsup _{n \rightarrow \infty} g\left(\left\|S y_{n}-x_{n}\right\|\right)=0$ and hence $\lim _{n \rightarrow \infty} g\left(\left\|S y_{n}-x_{n}\right\|\right)=0$.

Since $\left\|S y_{n}-x_{n}\right\| \leq 2\|x-w\|$ for all $n \in \mathbb{N},\left\{\left\|S y_{n}-x_{n}\right\|\right\}$ is bounded and hence we can put $M=\lim \sup _{n \rightarrow \infty}\left\|S y_{n}-x_{n}\right\|$. So there exists $\left\{\left\|S y_{n_{k}}-x_{n_{k}}\right\|\right\} \subset\left\{\left\|S y_{n}-x_{n}\right\|\right\}$ such that

$$
\lim _{k \rightarrow \infty}\left\|S y_{n_{k}}-x_{n_{k}}\right\|=M
$$

Since $g$ is a continuous function, we have

$$
0=\lim _{k \rightarrow \infty} g\left(\left\|S y_{n_{k}}-x_{n_{k}}\right\|\right)=g(M) .
$$

Since $g(0)=0$ and $g$ is strictly increasing, $M=0$.

Therefore, $\lim \sup _{n \rightarrow \infty}\left\|S y_{n}-x_{n}\right\|=0$ and hence $\lim _{n \rightarrow \infty}\left\|S y_{n}-x_{n}\right\|=0$.

From (3.4), we have

$$
\begin{aligned}
0 & \leq \alpha_{n}\left(1-\alpha_{n}\right) g\left(\left\|S y_{n}-x_{n}\right\|\right) \\
& \leq\left\|x_{n}-w\right\|^{2}-\left\|x_{n+1}-w\right\|^{2}+\alpha_{n}\left(\left\|y_{n}-w\right\|^{2}-\left\|x_{n}-w\right\|^{2}\right) .
\end{aligned}
$$

Hence,

$$
\alpha_{n}\left(\left\|x_{n}-w\right\|^{2}-\left\|y_{n}-w\right\|^{2}\right) \leq\left\|x_{n}-w\right\|^{2}-\left\|x_{n+1}-w\right\|^{2}
$$

Since $\alpha_{n}\left(1-\alpha_{n}\right)<\alpha_{n}$ for all $n \in \mathbb{N}, 0<\liminf _{n \rightarrow \infty} \alpha_{n}\left(1-\alpha_{n}\right)<\liminf _{n \rightarrow \infty} \alpha_{n}$.

Therefore, there exist $k_{2}>0$ and $N \in \mathbb{N}$ such that

$$
\alpha_{n} \geq k_{2}, \quad \forall n \geq N
$$

Then from (3.6) and $\lim _{n \rightarrow \infty}\left\|x_{n}-w\right\|$ exists, we have $\lim _{n \rightarrow \infty}\left(\left\|x_{n}-w\right\|^{2}-\left\|y_{n}-w\right\|^{2}\right)=0$.

On the other hand, we have from (3.2) that

$$
\beta_{n}\left(1-\beta_{n}\right) g\left(\left\|T x_{n}-x_{n}\right\|\right) \leq\left\|x_{n}-w\right\|^{2}-\left\|y_{n}-w\right\|^{2} .
$$

Since $\liminf _{n \rightarrow \infty} \beta_{n}\left(1-\beta_{n}\right)>0$ so there exist $k_{3}>0$ and $N \in \mathbb{N}$ such that

$$
\alpha_{n} \geq k_{3}, \quad \forall n \geq N
$$

Therefore, we can conclude that $\lim _{n \rightarrow \infty} g\left(\left\|T x_{n}-x_{n}\right\|\right)=0$. 
Similarly, the continuity and strictly convexity of $g$ imply that $\lim _{n \rightarrow \infty}\left\|T x_{n}-x_{n}\right\|=0$.

Since $\left\{x_{n}\right\}$ is bounded, there exists $\left\{x_{n_{i}}\right\} \subset\left\{x_{n}\right\}$ such that $x_{n_{i}} \rightarrow v$. From demiclosedness of $T$, we have $v \in F(T)$. Since

$$
\begin{aligned}
\limsup _{n \rightarrow \infty}\left\|y_{n}-x_{n}\right\| & =\limsup _{n \rightarrow \infty}\left\|\beta_{n} T x_{n}+\left(1-\beta_{n}\right) x_{n}-x_{n}\right\| \\
& =\limsup _{n \rightarrow \infty} \beta_{n}\left\|T x_{n}-x_{n}\right\|,
\end{aligned}
$$

where $\left\{\beta_{n}\right\} \subset(0,1)$ and $\lim _{n \rightarrow \infty}\left\|T x_{n}-x_{n}\right\|=0$, we have $\lim _{n \rightarrow \infty}\left\|y_{n}-x_{n}\right\|=0$.

Using $\lim _{n \rightarrow \infty}\left\|y_{n}-x_{n}\right\|=0$ and $x_{n_{i}} \rightarrow v$, by passing through subsequences, if necessary, we can assume that there exists a weakly convergent subsequence $\left\{y_{n_{i}}\right\}$ of $\left\{y_{n}\right\}$ such that $y_{n_{i}} \rightarrow v$.

Furthermore, consider

$$
\begin{aligned}
\left\|S y_{n}-y_{n}\right\| & =\left\|S y_{n}-x_{n}+x_{n}-y_{n}\right\| \\
& \leq\left\|S y_{n}-x_{n}\right\|+\left\|x_{n}-y_{n}\right\| .
\end{aligned}
$$

Since $\lim _{n \rightarrow \infty}\left\|S y_{n}-x_{n}\right\|=0$ and $\lim _{n \rightarrow \infty}\left\|y_{n}-x_{n}\right\|=0, \lim _{n \rightarrow \infty}\left\|S y_{n}-y_{n}\right\|=0$.

By the demiclosedness of $S$, we have $v \in F(S)$ and hence $v \in F(S) \cap F(T)$.

Finally, we show that $x_{n} \rightarrow v$. Let $\left\{x_{n_{k}}\right\}$ be arbitrary subsequence of $\left\{x_{n}\right\}$. Since $\left\{x_{n_{k}}\right\}$ is bounded, there exists $\left\{x_{n_{k_{i}}}\right\} \subset\left\{x_{n_{k}}\right\}$ that $x_{n_{k_{i}}} \rightarrow u$. The same proof as $v$ above, there exists $\left\{y_{n_{k_{i}}}\right\} \subset\left\{y_{n_{k}}\right\}$ such that $y_{n_{k_{i}}} \rightarrow u$ and $u \in F(S) \cap F(T)$.

Suppose that $v \neq u$. Using Lemma 3.6 to guarantee that $\lim _{n \rightarrow \infty}\left\|x_{n}-v\right\|$ and $\lim _{n \rightarrow \infty}\left\|x_{n}-u\right\|$ exist and hence we have from the Opial property that

$$
\begin{aligned}
\lim _{n \rightarrow \infty}\left\|x_{n}-v\right\| & =\lim _{i \rightarrow \infty}\left\|x_{n_{i}}-v\right\| \\
& <\lim _{i \rightarrow \infty}\left\|x_{n_{i}}-u\right\| \\
& =\lim _{n \rightarrow \infty}\left\|x_{n}-u\right\| \\
& =\lim _{i \rightarrow \infty}\left\|x_{n_{k_{i}}}-u\right\| \\
& <\lim _{i \rightarrow \infty}\left\|x_{n_{k_{i}}}-v\right\| \\
& =\lim _{n \rightarrow \infty}\left\|x_{n}-v\right\| .
\end{aligned}
$$

This is a contradiction. So $x_{n} \rightarrow v \in F(T) \cap F(S)$.

Since the class of nonspreading mappings for a general Banach space is different from the class of mappings satisfying condition (C), we can apply Proposition 2.5 and Proposition 3.3 to deduce Theorem 3.7 as follows:

Corollary 3.8 Let X be a uniformly convex Banach space having Opial property. Let $E$ be a nonempty closed convex subset of $X$. Assume that $S: E \rightarrow E$ is a nonspreading mapping for a general Banach space and $T: E \rightarrow E$ satisfies condition $(C)$ such that $F(S) \cap F(T) \neq \emptyset$. Let $\left\{x_{n}\right\}$ and $\left\{z_{n}\right\}$ be defined as

$$
\text { (A) }\left\{\begin{array}{l}
x_{1}=x \in E, \\
x_{n+1}=\alpha_{n} S\left\{\beta_{n} T x_{n}+\left(1-\beta_{n}\right) x_{n}\right\}+\left(1-\alpha_{n}\right) x_{n},
\end{array}\right.
$$


(B) $\left\{\begin{array}{l}z_{1}=z \in E \\ z_{n+1}=\alpha_{n} T\left\{\beta_{n} S z_{n}+\left(1-\beta_{n}\right) z_{n}\right\}+\left(1-\alpha_{n}\right) z_{n}\end{array}\right.$

for all $n \in \mathbb{N}$, where $\left\{\alpha_{n}\right\} \subset(0,1)$ and $\beta_{n} \subset(0,1)$.

If $\liminf _{n \rightarrow \infty} \alpha_{n}\left(1-\alpha_{n}\right)>0$ and $\liminf _{n \rightarrow \infty} \beta_{n}\left(1-\beta_{n}\right)>0$, then $\left\{x_{n}\right\}$ generated by $(A)$ and

$\left\{z_{n}\right\}$ generated by $(B)$ converge weakly to $u \in F(S) \cap F(T)$ and $v \in F(S) \cap F(T)$, respectively.

\section{Competing interests}

The authors declare that they have no competing interests.

Authors' contributions

All authors read and approved the final manuscript.

\section{Acknowledgements}

This article is dedicated to Professor Anthony To-Ming Lau for celebrating his great achievements in the development of fixed point theory and applications. The authors are indebted to the anonymous referee(s) for comments which lead to the improvement and for the kindness in providing us the open problem in the article. This research was (partially) supported by the Centre of Excellence in Mathematics, the Commission on Higher Education, Thailand.

Received: 24 April 2012 Accepted: 20 June 2012 Published: 10 July 2012

\section{References}

1. Diaz, JB, Metcalf, FT: On the structure of the set of subsequential limit points of successive approximations. Bull. Am. Math. Soc. 73, 516-519 (1967)

2. Suzuki, T: Fixed point theorems and convergence theorems for some generalized nonexpansive mappings. J. Math Anal. Appl. 340, 1088-1095 (2008)

3. Dhompongsa, S, Inthakon, W, Kaewkhao, A: Edelstein's method and fixed point theorems for some generalized nonexpansive mappings. J. Math. Anal. Appl. 350, 12-17 (2009)

4. Dhompongsa, S, Kaewcharoen, A: Fixed point theorems for nonexpansive mappings and Suzuki-generalized nonexpansive mappings on a Banach lattice. Nonlinear Anal. 71, 5344-5353 (2009)

5. Garcia-Falset, J, Llorens-Fuster, E, Suzuki, T: Fixed point theory for a class of generalized nonexpansive mappings. J. Math. Anal. Appl. 375, 185-195 (2011)

6. Nanjaras, B, Panyanak, B, Phuengrattana, W: Fixed point theorems and convergence theorems for Suzuki-generalized nonexpansive mappings in CAT(0) spaces. Nonlinear Anal. 4, 25-31 (2010)

7. Kohsaka, F, Takahashi, W: Fixed point theorems for a class of nonlinear mappings related to maximal monotone operators in Banach spaces. Arch. Math. 91, 166-177 (2008)

8. lemoto, S, Takahashi, K, Takahashi, W: A weak convergence theorem for nonexpansive mappings and nonspreading mappings in a Hilbert space. In: Akashi, S, Takahashi, W, Tanaka, T (eds.) Nonlinear Analysis and Optimization, pp. 75-85. Yokohama Publishers, Yokohama (2009)

9. lemoto, S, Takahashi, W: Approximating common fixed points of nonexpansive mappings and nonspreading mappings in a Hilbert space. Nonlinear Anal. 71, 2082-2089 (2009)

10. Igarashi, T, Takahashi, W, Tanaka, K: Weak convergence theorems for nonspreading mappings and equilibrium problems. In: Akashi, S, Takahashi, W, Tanaka, T (eds.) Nonlinear Analysis and Optimization, pp. 63-73. Yokohama Publishers, Yokohama (2009)

11. Takahashi, W, Tamura, T: Convergence theorems for a pair of nonexpansive mappings. J. Convex Anal. 5, 45-56 (1998)

12. Dhompongsa, S, Inthakon, W, Takahashi, W: A weak convergence theorem for common fixed points of some generalized nonexpansive mappings and nonspreading mappings in a Hilbert space. Optimization 6, 1-11 (2011)

13. Goebel, K, Kirk, WA: Topics in Metric Fixed Point Theory. Cambridge University Press, Cambridge (1990)

14. Opial, Z: Weak convergence of the sequence of successive approximations for nonexpansive mapping. Bull. Am. Math. Soc. 73, 591-597 (1967)

15. Xu, HK: Inequalities in Banach spaces with applications. Nonlinear Anal. 16, 1127-1138 (1991)

16. Lau, AT: Semigroup of nonexpansive mappings on a Hilbert space. J. Math. Anal. Appl. 105(2). 514-522 (1985)

17. Lau, AT, Zhang, Y: Fixed point properties of semigroups of nonexpansive mappings. J. Funct. Anal. 254(10), 2534-2554 (2008)

doi:10.1186/1687-1812-2012-110

Cite this article as: Inthakon et al.: Common fixed points for some generalized nonexpansive mappings and nonspreading-type mappings in uniformly convex Banach spaces. Fixed Point Theory and Applications 2012 2012:110. 